\title{
Controlled Silicon Surface Functionalization by Alkene Hydrosilylation
}

\author{
Alexander Langner, Anthony Panarello, Sandrine Rivillon, Oleksiy Vassylyev, \\ Johannes G. Khinast, and Yves J. Chabal
}

\section{Supporting information}

\section{Experimental details:}

Double-side polished n-doped silicon (111) and (100) wafers (resistivity $\sim 30$ $\Omega . \mathrm{cm})$ are cut from a $500 \mu \mathrm{m}$ thick sample with rectangular shapes for infrared spectroscopy. Each sample is cleaned according to the standard RCA procedure: immersion into 1) a solution of $\mathrm{H}_{2} \mathrm{O}: \mathrm{H}_{2} \mathrm{O}_{2}: \mathrm{NH}_{4} \mathrm{OH}$ (4:1:1 by volume), where $\mathrm{H}_{2} \mathrm{O}$ is deionized water (DIW) ( $\rho=18.2 \mathrm{M} \Omega . \mathrm{cm})$, and 2) a solution of $\mathrm{H}_{2} \mathrm{O}: \mathrm{H}_{2} \mathrm{O}_{2}: \mathrm{HCl}(4: 1: 1)$. In both cases, the solutions are heated for $10 \mathrm{~min}$ at $80^{\circ} \mathrm{C}$ and the silicon $(\mathrm{Si})$ samples are rinsed with profuse DIW after each steps. After these two standard cleans (SC-1 and SC2, respectively), ${ }^{1}$ the samples have a thin oxide $(\sim 8-10 \AA)$. Oxide-free, atomically flat $\mathrm{H}$ terminated $\mathrm{H} / \mathrm{Si}(111)$ are then obtained by etching with hydrofluoric acid $(\sim 20 \%)$ for 30 s, followed by etching in ammonium fluoride (49\%) for two and a half minutes. Oxidized, flat silicon (100) surface $\left(\mathrm{SiO}_{2} / \mathrm{Si}(100)\right)$ is hydrogen-terminated by immersing the sample after the SC-1 and SC-2 cleans (i.e. while they are still oxidized) in a solution of triethoxysilane and anhydrous toluene $(1: 19)$ at $80^{\circ} \mathrm{C}$ for at least 14 hours. In order to control the moisture, the experiments are performed in a nitrogen $\left(\mathrm{N}_{2}\right)$-purged glove box. To grow a thinner oxide layer ( $\sim 6 \AA$ ), H-terminated $\mathrm{Si}(100)$ samples (after HF etching) are immersed in $\mathrm{H}_{2} \mathrm{O}_{2}: \mathrm{H}_{2} \mathrm{SO}_{4}(1: 4)$ at $80^{\circ} \mathrm{C}$ for 10 minutes. Hydrogenation is then performed in a similar fashion (using triethoxysilane and anhydrous toluene).

Two different ways are used to immobilize the indene ligand (1-5 mg in $20 \mathrm{ml}$ solvent), shown in Fig. $\mathrm{S} 1$, onto the $\mathrm{H} / \mathrm{Si}(111)$ and $\mathrm{H} / \mathrm{SiO}_{2} / \mathrm{Si}(100$ : 1) the $\mathrm{H} / \mathrm{Si}$ samples

\footnotetext{
${ }^{1}$ Higashi, G. S., Chabal, Y. J. Silicon Surface Chemical Composition and Morphology in Handbook of semiconductor wafer cleaning technology, Kern, W., Ed.; Noyes publications: East Windsor, 1993 433-496
} 
are immersed in a solution of indene ligand with either IPA or chlorobenzene and 1-5 mg $\mathrm{H}_{2} \mathrm{PtCl}_{6}$ (as a catalyst) for 4 hours at $80^{\circ} \mathrm{C}$; and 2) the $\mathrm{H} / \mathrm{Si}$ surface, in solution with the indene ligand dissolved in chlorobenzene, is irradiated with UV-light (254 nm) 2 hours on each side in a $\mathrm{N}_{2}$-purged environment (the sample is turned over for irradiation of the other side at half-time). The immobilization is followed by a 5 min-sonication and a thorough-rinse in chlorobenzene to remove any molecules that have not reacted with the surface. Different UV wavelengths (254 and $365 \mathrm{~nm}$ ) and irradiation times (2, 4 and 6h) have been used (see section 3 and 4).

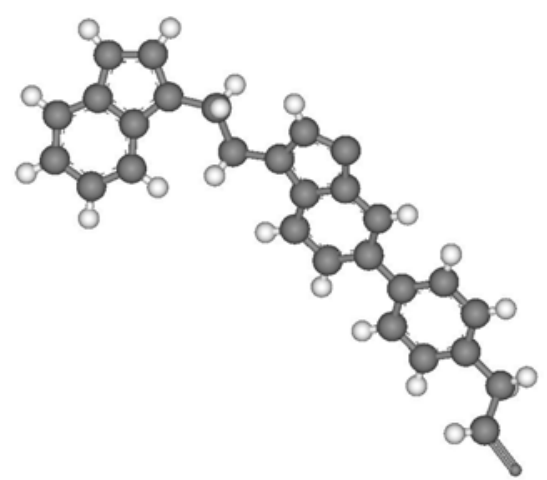

Figure S1. Indene ligand 


\section{Isopropanol reactivity with H-terminated surfaces:}

Figure S2 shows the results of immersion of $\mathrm{H} / \mathrm{Si}(111)$ (left panel) and $\mathrm{H} / \mathrm{SiO}_{2} / \mathrm{Si}(100)$ (right panel) in (a) isopropanol (IPA) only, (b) IPA with catalyst and (c) IPA with catalyst $\left(\mathrm{H}_{2} \mathrm{PtCl}_{6}\right)$ and indene ligand for $4 \mathrm{hr}$. All the spectra are reference to the initial $\mathrm{H}$-terminated $\mathrm{Si}$ surfaces, $\mathrm{H} / \mathrm{Si}(111)$ and $\mathrm{H} / \mathrm{SiO}_{2} / \mathrm{Si}(100)$ respectively, so that negative features indicate a loss of species.

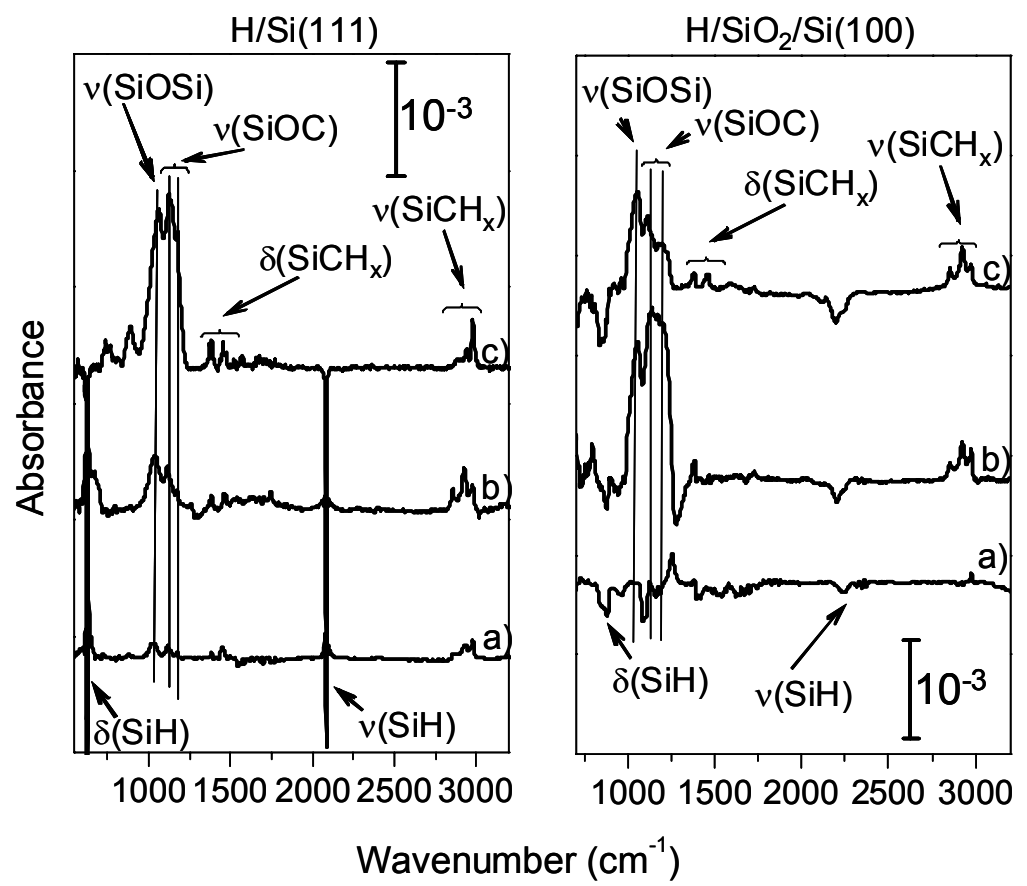

Figure S2. Transmission infrared spectra of a) isopropanol only, b) isopropanol and $\mathrm{H}_{2} \mathrm{PtCl}_{6}$, and c) isopropanol with $\mathrm{H}_{2} \mathrm{PtCl}_{6}$ and indene ligand on (left) $\mathrm{H} / \mathrm{Si}(111)$ and (right) $\mathrm{H} / \mathrm{SiO}_{2} / \mathrm{Si}(100)$

For $\mathrm{H} / \mathrm{Si}(111)$ surface, IPA clearly reacts with the surface: there is a loss of both stretching $\left(2083 \mathrm{~cm}^{-1}\right)$ and bending $\left(626 \mathrm{~cm}^{-1}\right) \mathrm{Si}-\mathrm{H}$ vibrations, indicating reaction of surface hydrogen, and absorbance features associated to IPA bonded to the Si surface are observed, such as the Si-O-C asymmetric stretching mode at $1116 \mathrm{~cm}^{-1}$, the Si-O-C rocking mode at $1174 \mathrm{~cm}^{-1}$, the $\mathrm{CH}_{\mathrm{x}}$ stretching modes in the $2800-2950 \mathrm{~cm}^{-1}$ region, and $\mathrm{CH}_{\mathrm{x}}$ deformation modes at 1382 and $1440 \mathrm{~cm}^{-1}$. More IPA reacts with the surface $(\sim 60 \%$ monolayer of $\mathrm{H}$ is removed) when the catalyst $\left(\mathrm{H}_{2} \mathrm{PtCl}_{6}\right)$ is used than for IPA $(\sim 25 \%$ of the hydrogen is removed). It therefore appears that the presence of $\mathrm{H}_{2} \mathrm{PtCl}_{6}$ promotes the reaction of IPA with the surface. Additionally, more Si-O-Si (silicon oxidation) is formed when the catalyst is present. When the ligand is added (Fig. c), the surface is fully reacted 
with alkyl groups (complete loss of hydrogen and presence of alkyl modes), with no evidence for ligand attachment.

Similar results are observed for the oxidized surface, $\mathrm{H} / \mathrm{SiO}_{2} / \mathrm{Si}(100)$ : IPA reacts without the presence of the catalyst $\left(\mathrm{H}_{2} \mathrm{PtCl}_{6}\right)$, and the indene ligand does not react.

\section{Time dependent studies of UV-light treatment:}

Transmission infra red spectra of the indene-ligand immobilization with UV-light (254 nm) are shown in Fig. S3 for different irradiation times: (a) $1 \mathrm{hr}$, (b) $2 \mathrm{hr}$, and (c) 3 hr for each side of the $\mathrm{H} / \mathrm{Si}(111)$ sample, for a total exposure of 2, 4, and 6 hours,

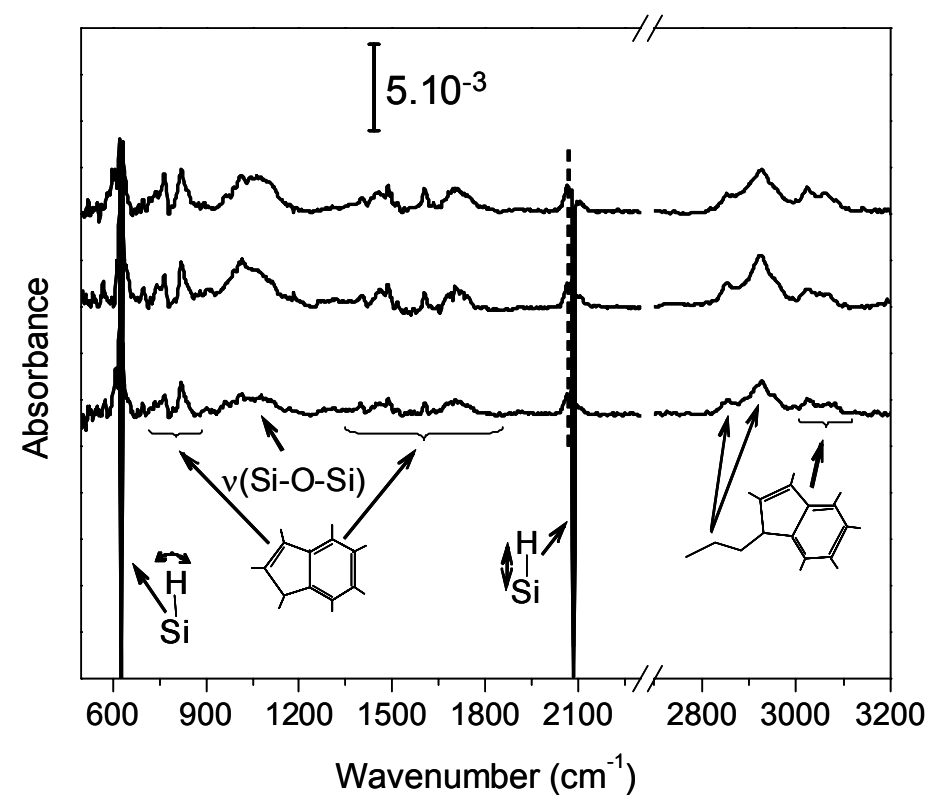

Figure S3. Transmission infrared spectra of chlorobenzene and indene ligand for different reaction times of UV irradiation: a) after $2 \mathrm{~h}, \mathrm{~b}$ ) $4 \mathrm{~h}$, and c) $6 \mathrm{~h}$ on $\mathrm{H} / \mathrm{Si}(111)$ surface.

respectively. The spectra presented are all referenced to the $\mathrm{H} / \mathrm{Si}(111)$ surface. Surface hydrogen is removed by reaction, as evidenced by the negative features at $2083 \mathrm{~cm}^{-1}$ (Si$\mathrm{H}$ stretch mode) and $626 \mathrm{~cm}^{-1}$ ( $\mathrm{Si}-\mathrm{H}$ bend mode), while absorbance features related to the indene ligand are clearly present: $750-900 \mathrm{~cm}^{-1}$ and $1300-1700 \mathrm{~cm}^{-1}$ are the bending mode regions, and 3000-3100 $\mathrm{cm}^{-1}$ the stretching mode region of the indene group. $\mathrm{C}-\mathrm{H}$ stretch modes are also observed between $2800-3000 \mathrm{~cm}^{-1}$. The hydrogen is not completely removed. Instead its environment changes as evidenced by broad features centered around $2065 \mathrm{~cm}^{-1}$ and $626 \mathrm{~cm}^{-1}$, typical of Si-H surrounded by reacted $\mathrm{Si}$ atoms. 
Using the total area of the $\mathrm{Si}-\mathrm{H}$ and oxide modes (see section 5 below), the amount of hydrogen reacted with the ligand can be estimated: a) after $2 \mathrm{hr}$ of UV exposure, about $25 \%$ of the hydrogen is lost, with $20 \%$ replaced by the indene ligand; b) after $4 \mathrm{hr}$ of UV exposure, $\sim 40 \%$ of hydrogen is removed and $30 \%$ of the total surface is functionalized with the organic ligand (maximum concentration observed); and c) after $6 \mathrm{hr}$ of UV exposure, there is no increase in ligand coverage or $\mathrm{H}$ loss. The broad feature observed at $1050 \mathrm{~cm}^{-1}$ corresponds to $\mathrm{Si}-\mathrm{O}-\mathrm{Si}$ bonds (silicon oxide). Comparing the integrated area to that of a $10 \AA$ oxide, we estimate the average thickness of the total amount of silicon oxide to $\sim 0.4 \AA$ but the surface area occupied by this oxide is $\sim 10 \%$.

\section{Wavelength dependence for the UV irradiation process on different surfaces:}

Figure S4 ( $a$ and $b$ ) compares the degree of indene ligand immobilization for two different UV wavelengths (365 nm and $254 \mathrm{~nm}$ ) on the oxide-free H/Si(111) surface, and Fig. S4(c) shows the result of $254 \mathrm{~nm}$ UV irradiation of the hydrogen on the oxidized surface, $\mathrm{H} / \mathrm{SiO}_{2} / \mathrm{Si}(100)$. For $\mathrm{S} 4$ ( $\mathrm{a}$ and b), the irradiation time is $4 \mathrm{hr}$. In both cases, all the indene-ligand features discussed earlier are present. However, the extent of the reaction varies: for $\lambda=365 \mathrm{~nm}$, only $30 \%$ of the surface hydrogen is removed $(\sim 20-25 \%$ ligand attached), while for $\lambda=254 \mathrm{~nm} \sim 40 \%$ of hydrogen is removed with $\sim 30 \%$ of the surface reacted with ligand. This indicates that the reaction rate is slower at $365 \mathrm{~nm}$ than at $254 \mathrm{~nm}$, resulting in a lower ligand coverage for similar irradiation times. Interestingly, less oxidation occurs with $365 \mathrm{~nm}$. In the absence of ligand, the $\mathrm{H} / \mathrm{Si}(111)$ surface in solution in chlorobenzene remains stable under UV irradiation with less than $3 \% \mathrm{H}$ removal after 2 hours irradiation on each side (4 hours in total).

Figure S4 (c) shows that no ligand immobilization occurs on $\mathrm{H} / \mathrm{SiO}_{2} / \mathrm{Si}(111)$ with $254 \mathrm{~nm}$ UV-light: absence of ligand features at $750-900 \mathrm{~cm}^{-1}, 1300-1700 \mathrm{~cm}^{-1}$ and 3000 $3100 \mathrm{~cm}^{-1}$ in spectrum S3(c). This observation, together with the data in Fig. 2(c) of the main article for the $\mathrm{H} / \mathrm{SiO}_{2} / \mathrm{Si}(100)$ surface, confirms that it is the presence of a thin oxide layer (and not the substrate orientation) that prevents ligand immobilization. The absence of ligand reaction under these conditions supports the electron-hole (exciton) model proposed in the main text. 


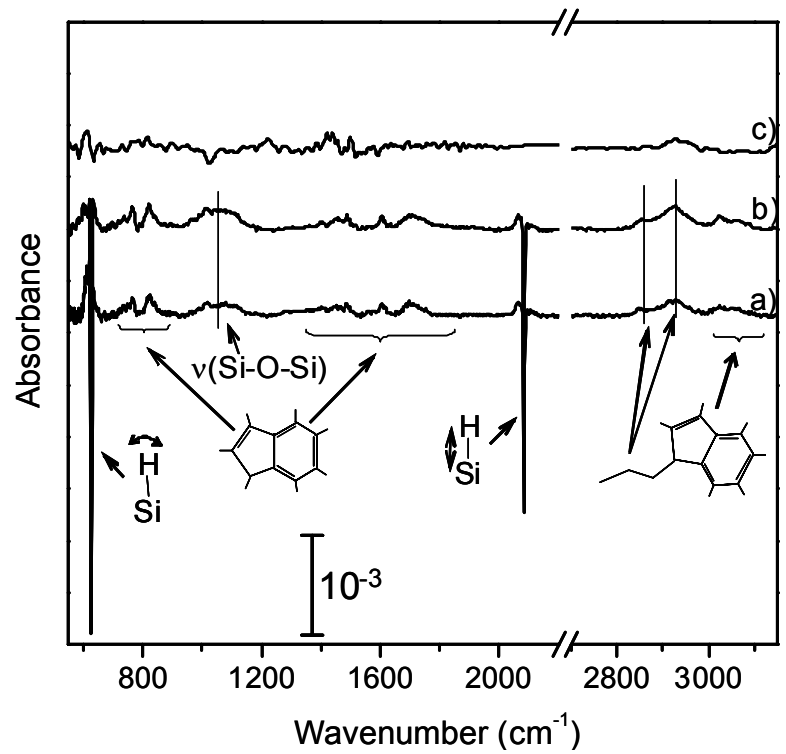

Figure S4. Transmission infrared spectra of chlorobenzene and indene ligand for different wavelengths of UV irradiation: a) $355 \mathrm{~nm}$, and b) $254 \mathrm{~nm}$ on $\mathrm{H} / \mathrm{Si}(111)$ surface, c) $254 \mathrm{~nm}$ on $\mathrm{H} / \mathrm{SiO}_{2} / \mathrm{Si}(100)$

\section{Estimation of the indene-ligand coverage:}

Estimating the ligand coverage is difficult because both ligand reaction (immobilization by hydrosilylation) and surface oxidation take place during the overall reaction cycle. The loss of hydrogen cannot therefore be strictly related to ligand reaction. To address this issue, a surface with the highest ligand coverage (i.e with $\sim 40 \%$ hydrogen removed) was exposed to air for 15 hours to further remove hydrogen by oxidizing the surface. The increase oxide absorption (Si-O-Si modes at $1050 \mathrm{~cm}^{-1}$ ) and the further loss of hydrogen (decrease of Si-H bending and stretching modes) were measured. The data show that $12 \%$ loss of the Si-H integrated area with an associate increase of $0.047 \mathrm{~cm}^{-1}$ for the integrated area of the Si-O-Si mode. From these data, the conversion between Si-O-Si integrated area and surface coverage is estimated to be $0.39 \mathrm{~cm}^{-1} /$ monolayer. Using this conversion, the area covered by oxide is found to be $\sim 10 \%$ when $40 \%$ of the $\mathrm{Si}-\mathrm{H}$ is removed, indicating that $30 \%$ of the surface has reacted with the indene ligand. 


\section{Stability of the indene ligand:}

Since both ligand immobilization and silicon oxidation take place under most reaction conditions, the surface is not perfectly homogeneous. It is therefore important to investigate the stability of the immobilized indene ligand to chemical attack, including $\mathrm{HF}$ etching. The $\mathrm{H} / \mathrm{Si}(111)$ surface with $\sim 30 \%$ immobilized ligand (Fig. S5a) was subjected to very harsh basic (SC-1) and acidic (SC-2) oxidizing treatments ${ }^{2}$ consisting of $\mathrm{H}_{2} \mathrm{O}: \mathrm{H}_{2} \mathrm{O}_{2}: \mathrm{NH}_{4} \mathrm{OH}(4: 1: 1)$ and $\mathrm{H}_{2} \mathrm{O}: \mathrm{H}_{2} \mathrm{O}_{2}: \mathrm{HCl}(4: 1: 1)$, respectively, at $80^{\circ} \mathrm{C}$ for 10 minutes each, with thorough DWI rinsing prior and following each treatment. Such procedures are effective to remove hydrocarbons, metallic impurities and particles and

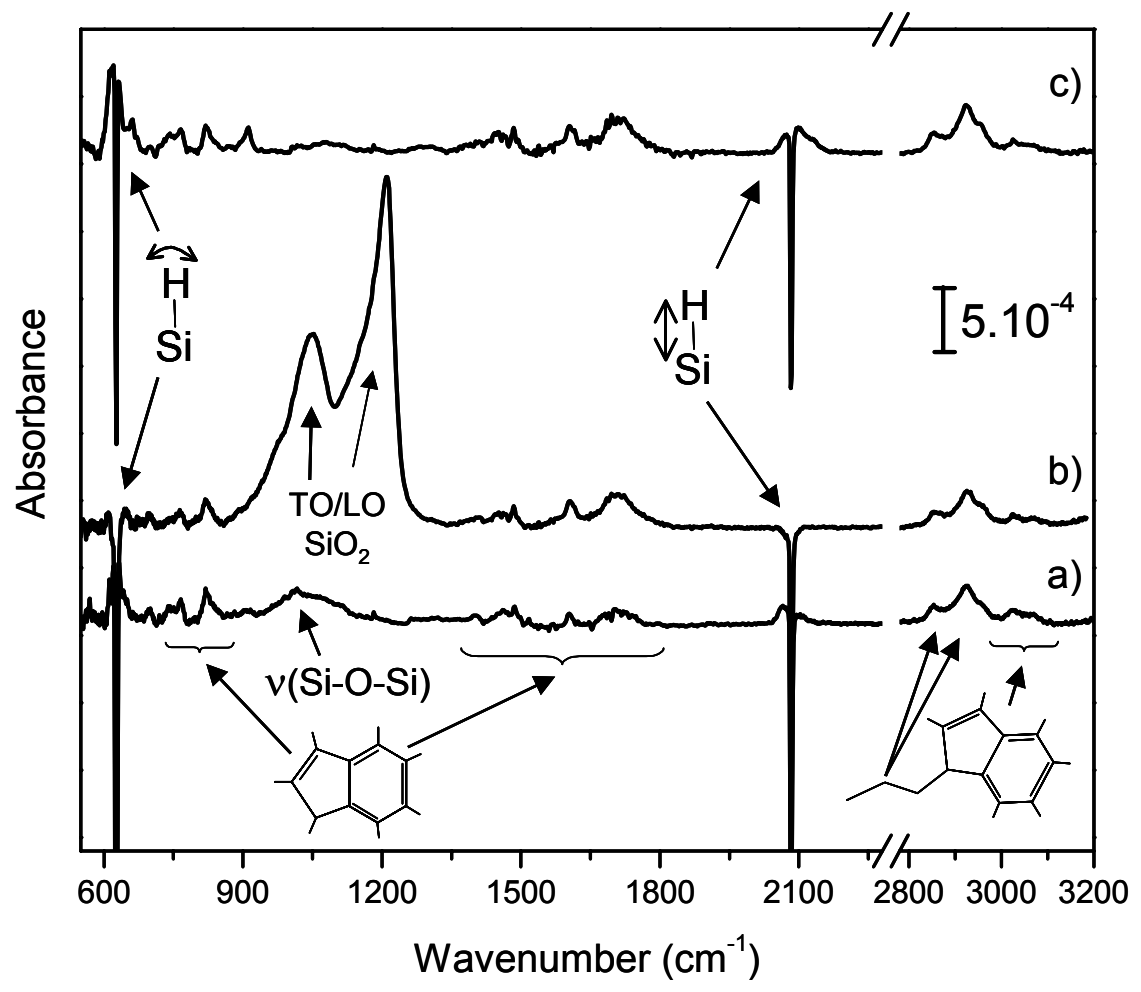

Figure S5. Transmission infrared spectra of chlorobenzene and indene ligand using UV light as a catalyst on $\mathrm{H} / \mathrm{Si}(111)$ a) before any etching, b) after SC-1 and SC-2 treatments, and c) $\mathrm{SC}-1$ and $\mathrm{SC}-2$ treatments followed by HF etching, on $\mathrm{H} / \mathrm{Si}(111)$ surface.

usually result in complete oxidation of silicon surfaces. Fig. S5(b) shows strong $\mathrm{SiO}_{2} \mathrm{TO}$

\footnotetext{
${ }^{2}$ Higashi, G. S., Chabal, Y. J. Silicon Surface Chemical Composition and Morphology in Handbook of semiconductor wafer cleaning technology, Kern, W., Ed.; Noyes publications: East Windsor, 1993 433-496
} 
and LO phonon bands, but there is no evidence for removal of the indene ligand. When this oxidized surface is immersed in HF, the oxide is completely removed, but again the ligand remains unperturbed. These remarkable results show that the $\mathrm{Si}-\mathrm{C}$ bond between the indene ligand and the substrate is resistant to the harshest chemical treatments.

\section{Activity of catalyst in chlorobenzene:}

Both $\mathrm{H} / \mathrm{Si}(111)$ and $\mathrm{H} / \mathrm{SiO}_{2} / \mathrm{Si}(100)$ show evidence of indene reaction when the hydrogen-terminated Si surface is immersed in chlorobenzene with $\mathrm{H}_{2} \mathrm{PtCl}_{6}$ as a catalyst. Stretching and bending modes related to the indene ligand molecules are clearly observed (see Figure $\mathrm{S} 6$ ). On $\mathrm{H} / \mathrm{Si}(111)$, the removal of hydrogen is complete and $\sim 25 \%$ of ligand molecules are bonded to the surface suggesting that $\sim 75 \%$ of the silicon surface form SiO-Si bond. For $\mathrm{H} / \mathrm{SiO}_{2} / \mathrm{Si}(100)$, about $55 \%$ of $\mathrm{SiH}$ has reacted, with about $\sim 20 \% \mathrm{ML}$ of ligand attached. Since the reference is the $\mathrm{H} / \mathrm{SiO}_{2} / \mathrm{Si}(100)$ surface, the negative feature at $2960 \mathrm{~cm}^{-1}$ is attributed to ethoxy groups from the triethoxysilane that have not reacted.

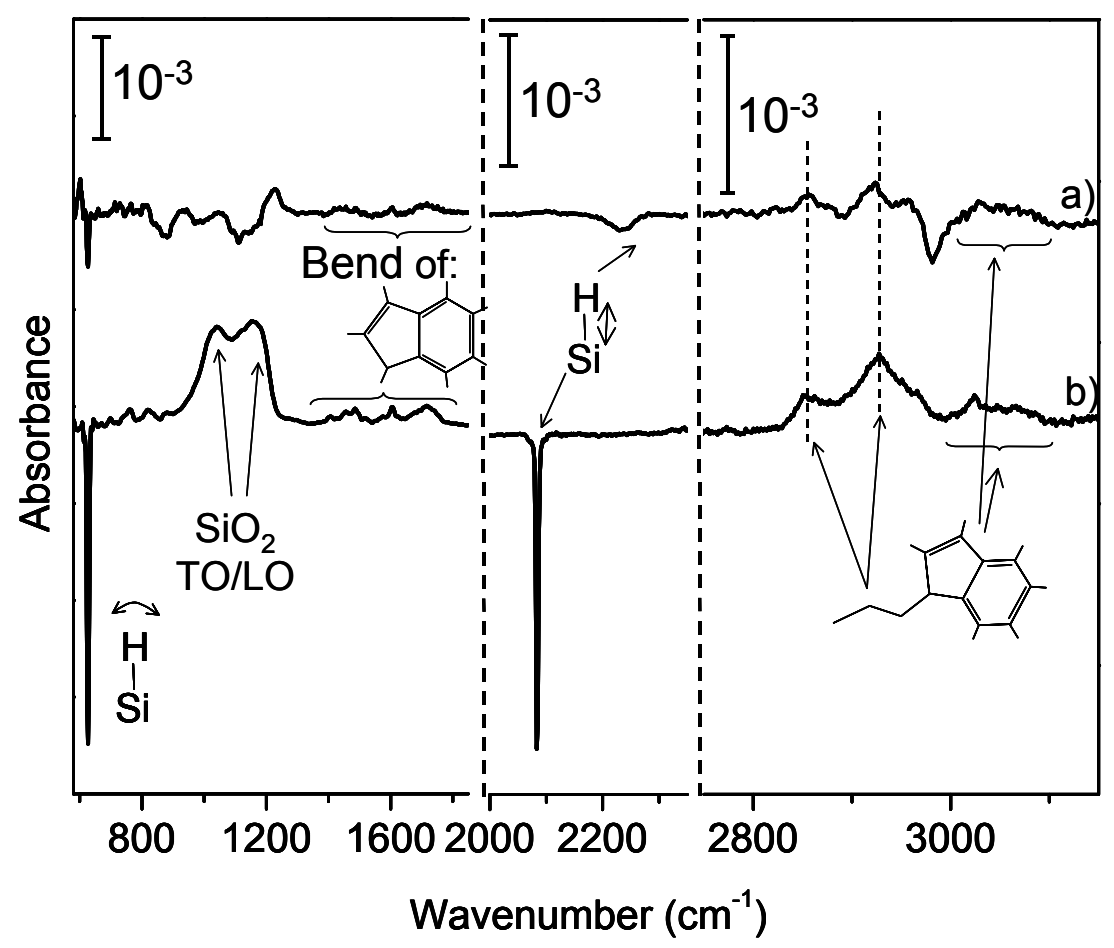

Figure S6. Transmission infra red spectra of chlorobenzene, indene ligand using $\mathrm{H}_{2} \mathrm{PtCl}_{6}$ as a catalyst on a) $\mathrm{H} / \mathrm{SiO} 2 / \mathrm{Si}(100)$ and b) $\mathrm{H} / \mathrm{Si}(111)$ 